The Designer Leptin Antagonist Peptide Allo-aca Compensates for Short Serum Half-life with Very Tight Binding to the Receptor

Laszlo Otvos, Jr, ${ }^{\text {a }}$ Stefan W. Vetter, ${ }^{\mathrm{b}}$ Mohit Koladia, ${ }^{\mathrm{b}}$ Daniel Knappe, ${ }^{\mathrm{c}}$ Rico Schmidt, ${ }^{\mathrm{c}}$ Eszter Ostorhazi, ${ }^{\mathrm{d}}$ Ilona Kovalszky, ${ }^{\mathrm{e}}$ Nina Bionda, ${ }^{\mathrm{f}}$ Predrag Cudic, ${ }^{\mathrm{f}}$ Eva Surmacz, ${ }^{\mathrm{g}}$ John D. Wade ${ }^{\mathrm{h}}$ and Ralf Hoffmann ${ }^{\mathrm{c}}$

${ }^{\mathrm{a}}$ Department of Biology and ${ }^{\mathrm{g}}$ Sbarro Institute of Cancer Research and Molecular Therapeutics, Temple University, Philadelphia, PA 19122, USA;

${ }^{\mathrm{b}}$ Department of Pharmaceutical Sciences, North Dakota State University, Fargo, ND 58102, USA;

${ }^{\mathrm{c}}$ Institute of Bioanalytical Chemistry, Faculty of Chemistry and Mineralogy, Center for Biotechnology and Biomedicine, Universität Leipzig, Leipzig 04103, Germany;

${ }^{\mathrm{d}}$ Department of Dermatology, Venerology and Dermatooncology and ${ }^{\mathrm{e}} 1^{\text {st }}$ Institute of Pathology and Experimental Cancer Research, Faculty of Medicine, Semmelweis University, 1085

Budapest, Hungary;

f Torrey Pines Institute for Molecular Studies, Port St Lucie, FL 34987, USA;

${ }^{\mathrm{h}}$ Florey Institute of Neuroscience and Mental Health, Victoria 3010, Australia

Corresponding Author

*Laszlo Otvos, Department of Biology, Temple University, 1900 North 12th Street, Philadelphia, PA 19122, USA. Phone: +1-215-204-4020; Fax: +1-215-204-6646; E-mail: otvos@temple.edu

\title{
ABSTRACT
}

The leptin receptor antagonist peptide Allo-aca exhibits picomolar activities in various cellular systems and sub-mg/kg subcutaneous efficacies in animal models making it a prime drug candidate and target validation tool. Here we identified the biochemical basis for its remarkable in vivo activity. Allo-aca decomposed within $30 \mathrm{~min}$ in pooled human serum and was undetectable beyond the same time period from mouse plasma during pharmacokinetic measurements. The $\mathrm{C}_{\max }$ of $8.9 \mu \mathrm{g} / \mathrm{mL}$ at 5 min corresponds to approximately $22 \%$ injected peptide present in the circulation. The half-life was extended to over $2 \mathrm{~h}$ in bovine vitreous fluid and $10 \mathrm{~h}$ in human tears suggesting potential efficacy in ophthalmic diseases. The peptide retained picomolar anti-proliferation activity against a chronic myeloid leukemia cell line; addition of a $\mathrm{C}$-terminal biotin label increased the $\mathrm{IC}_{50}$ value by approximately 200 -fold. In surface plasmon resonance assays with the biotin-labeled peptide immobilized to a NeutrAvidincoated chip, Allo-aca exhibited exceptionally tight binding to the binding domain of the human leptin receptor with $k_{\mathrm{a}}=5 \times 10^{5} \mathrm{M}^{-1} \mathrm{~s}^{-1}$ and $k_{\text {diss }}=1.5 \times 10^{-4} \mathrm{~s}^{-1}$ values. Peptides excel in terms of high activity and selectivity to their targets, and may activate or inactivate receptor functions considerably longer than molecular turnovers take place in experimental animals. 
Keywords

Antiproliferation, Dissociation constant, Metabolic stability, Peptide therapeutics, Receptor activation

\section{UNCOMMON ABBREVIATIONS}

$\mathrm{A} \beta$, amyloid $\beta$ peptide

CML, chronic myeloid leukemia;

Dde, dimethyl-dioxo-cyclohexylidene;

EDTA, ethylene diamine tetraacetate;

Fmoc, fluorenyl-methoxycarbonyl;

G-CSF, granulocyte-colony stimulating factor;

IL-6, interleukin-6;

ip, intraperitoneally;

LBD, leptin binding domain;

LOQ, limit of quantification;

MALDI TOF-MS, matrix-assisted laser ionization/desorption time-of-flight mass spectrometry;

ObR, leptin receptor;

PK, pharmacokinetics;

RP-HPLC, reversed-phase high performance liquid chromatography;

TCA, trichloroacetic acid;

TFA, trifluoroacetic acid;

TNBC, triple negative breast cancer;

sc, subcutaneously;

SPR, surface plasmon resonance

\section{INTRODUCTION}

Leptin is a neurohormone that acts in the hypothalamus and regulates energy balance and food intake (Wauters et al. 2000), and thus the leptin/leptin receptor (ObR) system is considered a prime pharmaceutical target (Inui and Meguid 2003). Central leptin deficiency or inefficient activity of endogenous leptin leads to obesity and hyperinsulinemia, and has been linked to infertility, impaired cognitive function, and osteoporosis (Kalra 2008). On the other hand, leptin signaling in specific peripheral tissues promotes cancer development (Gonzalez et al. 2006). Similar to other hormone receptors involved in metabolic functions and appetite control such as adiponectin (Otvos at al. submitted) and ghrelin (Moulin et al. 2013) ObR antagonists are being developed either as mutants of the full protein or peptide fragments representing single receptor binding sites. Superposition of leptin's sequence with other cytokines, such as human IL-6 (interleukin-6), bovine G-CSF (granulocyte-colony stimulating factor) or human oncostatin M reveals three potential bivalent ObR binding sites (sites I-III) (Peelman et al. 2004). While site I protein mutants do exhibit orexigenic properties (Shpilman et al. 2011), a site II-derived peptide 
inhibits the growth of cells xenotransplanted into immunocompromised mice, and reduces the level of pro-angiogenic and pro-proliferative markers (Gonzalez et al. 2009). However, none of the site I and site II-derived leptin derivative peptides is a pure antagonist, i.e., lacks agonistic properties without leptin present (Otvos et al. 2008).

We developed a family of 9-10-amino acid long peptide analogs of ObR-binding site III of leptin that act as selective ObR inhibitors without any partial agonistic activity within a 1000-fold concentration increase range (Otvos et al. 2011a). The lead peptide-based therapeutic called Allo-aca (Table 1) reduces leptin-dependent growth and signaling in hormone-positive and negative breast cancer cell lines with $\mathrm{IC}_{50}$ values of 50-200 pM [9-10]. Allo-aca is orexigenic in mice when added intraperitoneally (ip) or subcutaneously (sc) (Otvos et al. 2011b). In immunocompromised mice Allo-aca suppresses the growth of established hormone-sensitive orthotopic human breast cancer xenografts by $45-51 \%$ when administered either ip or sc for 38 days at a dose as low as $0.1 \mathrm{mg} / \mathrm{kg} /$ day (Otvos et al. 2011a). In human triple negative breast cancer (TNBC) xenografts, Allo-aca administered sc significantly extends the average survival time from 15.4 days (untreated controls) to 24 and 28.1 days at 0.1 and $1 \mathrm{mg} / \mathrm{kg} / \mathrm{day}$ doses, respectively (Otvos et al. 2011b). Particularly attractive with Allo-aca, and probably other ObR antagonists, is its ability to interfere with cancer development at multiple stages. In the TNBC model, the survival figures are more impressive than the primary tumor growth inhibition data. This can be due to at least partial inhibition of metastasis and angiogenesis and perhaps delaying systemic inflammatory processes (Otvos and Surmacz 2011). Indeed, Allo-aca reduces the levels of rheumatoid arthritis (RA) development markers in murine models, which is quite understandable as many molecular mechanisms in RA and cancer are dramatically similar (Otvos et al. $2011 \mathrm{c}$ ). Most recently, leptin-dependent proliferation of monkey retinal and bovine corneal endothelial cells was inhibited with mid-nanomolar concentrations of peptide Allo-aca suggesting potential therapy opportunities in ophthalmic diseases (Scolaro et al. 2013). As a target validation tool, Allo-aca had a major role to document that leptin protein protects hippocampal neurons from amyloid $\beta$ protein $(A \beta)$-induced cell death through ObR activation (Martins et al. 2013). As far as we know, in addition to our laboratories, the peptide is currently under study as a therapeutic option or as a target validation reagent internationally in over 10 institutions.

What missing from the complete evaluation of the pharmaceutical utility of Allo-aca was the characterization of two basic biochemical properties: the quantitation of molecular interactions (as opposed to the heavily studied cellular activity in ObR-expressing cells) between the peptide and isolated $\mathrm{ObR}$ and stability of the peptide in various biological media where the activity in vivo is manifested. Here we show that the driving force behind the remarkable animal efficacy data of Allo-aca is its extremely strong binding to ObR.

\section{MATERIALS AND METHODS}

Peptide synthesis. The Allo-aca and Allo-aca(biotin) peptides were synthesized by solid-phase methods. The peptide chain assembly was made on a CEM Liberty microwave-assisted (Alloaca) or a Protein Technologies PS3 (biotin-labeled analog) automated synthesizers using TentaGel S-Ram-Fmoc resin with an initial load of 0.3 mmole/g (Rapp Polymere). Standard 
Fmoc-chemistry was used throughout (Fields and Noble 1990) with a 4-molar excess of the acylating amino acids. For biotin labeling, the C-terminal lysine was incorporated as FmocLys(Dde)-OH, the side-chain protecting group was removed with $2 \%$ hydrazine, and biotin was coupled overnight as a preformed $\mathrm{N}$-hydroxy succinimide ester in $\mathrm{N}$-methyl morpholine and diisopropyl ethylamine. Both unlabeled and labeled peptides were cleaved from the solid support with trifluoroacetic acid (TFA) in the presence of thioanisole (5\%), and water (5\%) as scavengers. After cleavage, the peptides were purified by reversed-phase high performance liquid chromatography (RP-HPLC) and the final products were characterized by RP-HPLC and matrix-assisted laser ionization/desorption time of flight mass spectrometry (MALDI TOF-MS). Allo-aca: H-alloThr-Glu-Nva-Val-Ala-Leu-Ser-Arg-Aca- $\mathrm{NH}_{2}$; Allo-aca(biotin): H-alloThr-GluNva-Val-Ala-Leu-Ser-Arg-Aca-Lys(biotin)- $\mathrm{NH}_{2}$, where alloThr is allo-threonine, Nva is norvaline, and Aca is 6-amino-caproic acid.

Cancer cell proliferation. Although MCF-7 cells are estrogen-dependent for growth in vivo, in vitro the cells proliferate well without estrogen added (Otvos et al. 2008). Thus, MCF-7 breast cancer and K-562 chronic myeloid leukemia (CML) cells were grown in standard media.

Seventy-five thousand MCF-7 and 100000 K-562 cells grown in RPMI 1640 medium containing $10 \%$ FBS (MCF-7) or $0.5 \%$ bovine serum albumin, BSA (K-562) were seeded into wells of 24well culture plates. Twenty-four h later the medium for MCF-7 cells was replaced to that used for K-562 cells. After an additional $24 \mathrm{~h}$ the wells were treated with $6 \mathrm{nM}$ leptin (R\&D Systems), various concentrations of peptides or a mixture of $6 \mathrm{nM}$ leptin and a dilution series of peptides. Cell numbers were counted under a microscope $72 \mathrm{~h}$ after ObR ligand addition. The assays were run in triplicates and repeated once.

Serum stability. For serum stability studies (Powell et al. 1993), $250 \mu \mathrm{L}$ of an aqueous Allo-aca stock solution $(0.8 \mathrm{mg} / \mathrm{mL})$ was added to $2.5 \mathrm{~mL} 25 \%$ aqueous pooled human serum in triplicate. The peptide-serum mixtures were thermostated at $37^{\circ} \mathrm{C}$. After $0,45,90,120,240$, and $480 \mathrm{~min}$, serum proteins from aliquots $(210 \mu \mathrm{L})$ were precipitated by the addition of $40 \mu \mathrm{L} 15 \%$ aqueous trichloroacetic acid (TCA). The samples were centrifuged and $220 \mu \mathrm{L}$ aliquots of the supernatants were analyzed on RP-HPLC. This well-established protocol was satisfactory for in vitro serum stability studies without the modifications needed for quantitative analysis of vitreous fluid and tear in vitro and mouse plasma in vivo (vide infra).

Vitreous fluid and tear stability assay. Extension of serum stability studies to other tissues was inspired by an earlier LC-MS study on peptide hormones in rat kidney, lung and liver homogenates (Liao et al. 201). Vitreous fluid was extracted from fresh bovine eyes obtained at a slaughterhouse in Budapest, Hungary. The two eyes of the same cow were sterilized (Octenisept spray, Schulke) on the surface and the vitreous fluid (approximately $1 \mathrm{~mL}$ from each eye) was extracted with a 20 gauge needle. Tear production of a laboratory volunteer was stimulated by inhalation of freshly cut onion vapors. Up to $200 \mu \mathrm{L}$ tear fluid was collected with a sterile transfer pipette and stored at $-18{ }^{\circ} \mathrm{C}$ until use. Aqueous Allo-aca solutions $(1 \mu \mathrm{g}$ in $10 \mu \mathrm{L})$ were mixed with $93 \mu \mathrm{L}$ vitreous or tear fluid in $0.5 \mathrm{~mL}$ Eppendorf tubes and incubated at $37^{\circ} \mathrm{C}$ at 500 rpm. After $0,1,4$ and $8 \mathrm{~h} 34 \mu \mathrm{L}$ aliquots were mixed with $114 \mu \mathrm{L} 89 \%$ aqueous acetonitrile containing 1\% formic acid and incubated for 10-30 min on ice. The precipitated proteins were separated by centrifugation (10 min, 12000 x g, Eppendorf MiniSpin). The supernatant (140 $\mu \mathrm{L})$ was dried by vacuum centrifugation (SpeedVac, Eppendorf) and the residue was dissolved in 
$3 \%$ aqueous acetonitrile containing $0.1 \%$ TFA $(120 \mu \mathrm{L})$. After centrifugation $(5 \mathrm{~min}, 12000 \mathrm{x}$ g, Eppendorf MiniSpin) a $100 \mu \mathrm{L}$ solution was analyzed by RP-HPLC using a Jupiter C-18 column $(2.0 \mathrm{~mm}$ inner diameter, $150 \mathrm{~mm}$ length, $5 \mu \mathrm{m}$ particle size, $30 \mathrm{~nm}$ pore size; Phenomenex, Torrance) on a Beckman Gold HPLC System. The gradient from 0.1\% TFA in water (eluent A) to $60 \%$ acetonitrile in $0.1 \%$ aqueous TFA (eluent B) was developed using $5 \%$ to $56 \% \mathrm{~B}$ in $17 \mathrm{~min}$. The assays were run in triplicates in two independent assays using vitreous fluids obtained from different eyes, and tears separately collected from the same donor.

Mouse pharmacokinetics (PK). Eight female CD-1 mice of $20 \mathrm{~g}$ were each inoculated sc with $40 \mu \mathrm{g}$ peptide Allo-aca ( $2 \mathrm{mg} / \mathrm{kg}$ total body weight) dissolved in sterile saline solution at 0.2 $\mathrm{mg} / \mathrm{mL}$. Blood (approximately $50 \mu \mathrm{L}$ ) was taken from the tail vein at $0,2,5,10,30,60,120$ and 240 min after drug administration into serum separator tubes containing EDTA. Each mouse was used 3 times, allowing sample collection in triplicates in each timepoint. Animals were maintained and handled in accordance with the recommendations of the Guidelines for the Care and Use of Laboratory Animals and were approved by the Animal Care Committee of Semmelweis University (permission No.: 22.1/1159/3/2010).

The tubes were centrifuged for $3 \mathrm{~min}$ at $8000 \mathrm{rpm}$ and frozen until analysis. Before Allo-aca concentration-determination the proteins were precipitated by mixing the plasma samples with aqueous acetonitrile (89\%) containing aqueous formic acid (1\%) (1:4, v/v). The samples were filtrated on 96-well Strata Plate (Phenomenex), dried under vacuum (room temperature) and dissolved in $3 \%$ aqueous acetonitrile containing $0.1 \%$ formic acid. Allo-aca was quantified by a combination of MS and RP-HPLC. MS was run on a QSTAR instrument using an extracted ion chromatogram of $[\mathrm{M}+2 \mathrm{H}]^{2+}(\mathrm{m} / \mathrm{z}, 493.76 \pm 0.25)$. Internal standard was the analog ObR agonist peptide E1/Aca with $m / z 846.22 \pm 0.25$ of $[\mathrm{M}+2 \mathrm{H}]^{2+}$. For RPC, peptides were separated on an Ultimate nanoHPLC operated at a flow rate of $200 \mu \mathrm{L} / \mathrm{min}$ using an Aqua $\mathrm{C}_{18}$-column $(2 \mathrm{~mm}$ internal diameter, $150 \mathrm{~mm}$ length, $3 \mu \mathrm{m}$ particle diameter, $12.5 \mathrm{~nm}$ pore size). The gradient was developed from $3 \%$ to $95 \%$ aqueous acetonitrile containing $0.1 \%$ formic acid. The analysis relied on a single calibration curve and 2 sets of sample analyses. Before MS and HPLC, the samples from identical time points were combined and re-divided into 2 parts. Figure 2 shows the results of the first assay; the second assay yielded similar results albeit with slightly lower peptide concentrations due to the repeated freezing-thawing and sample manipulation processes.

Surface plasmon resonance (SPR). The leptin binding domain (LBD, residues 428-635) of human ObR was cloned into a pEX vector (OriGene), expressed in Escherichia coli SHuffle T7 Express cells (NEB Biolabs) and purified following previously published methods (Sandowski et al. 2002; Carpenter et al. 2012). SPR measurements were performed using a SR7500DC instrument from Reichert Technologies (Buffalo, New York). NeutrAvidin surface sensors (Reichert) were used to immobilize biotinylated Allo-aca on the left flow channel $\mathrm{L}$. The right flow channel (R) of the sensor chip was used as reference channel. TBST (50 mM Tris, $150 \mathrm{mM}$ $\mathrm{NaCl}, 0.002 \%$ Tween 20, $\mathrm{pH}$ 7.4) was used as running and dilution buffer for ObR-LBD in all experiments. SPR traces were acquired at a flow rate of $25 \mu \mathrm{L} / \mathrm{min}$ at a constant temperature of $25.0^{\circ} \mathrm{C}$ using the Integrated SPR Autolink software (Reichert) and were analyzed using Scrubber 2.0 (BioLogic Software, Campbell, Australia) and ClampXP to calculate kinetic rate constants. The experiment was repeated 10 times with very consistent results. 


\section{RESULTS}

Anti-cancer cell proliferation. To verify that the C-terminally biotin-labeled Allo-aca analog retains ObR antagonist properties and such can be used in the SPR assay to study receptorpeptide ligand interactions, the ability of the labeled peptide to inhibit MCF-7 cell growth was compared to that of the unmodified and previously heavily studied parent analog Allo-aca. As the main theme of the stability/PK studies is the concentration level of Allo-aca in blood preparations, we also wanted to see if the peptides can be developed as drugs to hematological malignancies and what concentrations are needed to inhibit the growth of leukemia cells. For this latter purpose we selected the K-562 CML cell line that produces ObR mRNA, albeit the expression level of various ObR forms are greatly reduced in CML patients (Ozturk et al. 2012). The $500 \mathrm{pM} \mathrm{IC}_{50}$ value of Allo-aca against MCF-7 cells, as we detected here (Table 2), is in the range of data we published earlier (200 pM). Similar to earlier results (Otvos et al. 2011a), the peptide did not induce cell proliferation without leptin added (no agonistic activity) up to the 100 $\mathrm{nM}$ maximal peptide concentration studied. Addition of the biotin label increased the $\mathrm{IC}_{50}$ figure to $100 \mathrm{nM}$ (a 200-fold decrease in activity) indicating that Allo-aca has a close-to-optimal size as an ObR antagonist (see Discussion for design of the SPR probe). In the first K-562 cell assay, leptin induced a 10\% additional cell growth during the 3-day examination period, that is approximately half of its effects on MCF-7 cells (data not shown). This finding confirms the low ObR expression level in K-562 cells (Ozturk et al., 2012). Allo-aca was more active against the $\mathrm{K}-562$ cell line than against MCF-7, exhibiting $\mathrm{IC}_{50}$ values at the low pM range (Table 2). Biotin-labeling reduced the activity figure by 200-fold, similar to those observed for MCF-7 proliferation inhibition. However, as opposed to MCF-7 cells, unlabeled Allo-aca was mitogenic to the CML cell line at $10 \mathrm{nM}$ concentration with and without $6 \mathrm{nM}$ leptin present. This suggests that not only the activity improved from going from solid to hematologic tumors, but also the antagonist $\rightarrow$ agonist switch occurred at lower concentrations. K-562 cells express low and variable level of ObR and unknown amounts of endogenous leptin protein. In our second assay identical $\mathrm{IC}_{50}$ values were measured for both peptides [Allo-aca and Allo-aca(biotin)] but the cell growth inhibitory effects were retained even if leptin was not added to the cell culture indicating that the peptide is a strong enough ObR antagonist to counteract the growth-promoting effects of leptin produced by K-562 cells themselves. Alternatively, similar to many other leptin-derived peptides against MCF-7 cells (Otvos et al. 2008), Allo-aca acts as an inverse ObR agonist in K562 cells.

Stability in various biological fluids. Up to today serum stability represented the most important secondary screening assay in drug development because it filtered out drug leads that were unstable in the circulation and had a predictive value to ensuing human and veterinary efficacy trials (Powel et al. 2012). Due to the desirable activity of Allo-aca in ophthalmic disease models, we also characterized the stability in bovine vitreous fluid and human tears. The altered experimental conditions were implemented to better quantify the presence of the peptide in these fluids and the degradation kinetics. In spite of the positioning of non-natural amino acids into terminal positions, Allo-aca was rapidly degraded in human serum. The half-life in $25 \%$ pooled aqueous serum was measured to $36 \mathrm{~min}$, representing $\mathrm{t}_{1 / 2}$ of $9 \mathrm{~min}$ in full serum (Table 2). These results are in agreement with the generally observed minutes-to-hours peptide stability in human plasma in general (Werle and Bernkop-Schnurch 2006). Allo-aca stability in 
bovine vitreous fluid was significantly increased and the $\mathrm{t}_{1 / 2}$ figure was extended to over $2 \mathrm{~h}$ (Table 2 and Figure 1). Even further stability was detected in human tears when the calculated half-life was extended to over $10 \mathrm{~h}$ (Table 2). It has to be mentioned that irritant-induced tears contain less peptide- or protein-like molecules than emotional tears (Frey et al. 1981) although the level of proteolytic enzymes is unlikely to be significantly different.

Pharmacokinetics in mice. When administered to CD-1 mice at a $2 \mathrm{mg} / \mathrm{kg}$ bolus sc dose, Alloaca appeared in low concentration $(34 \mathrm{ng} / \mathrm{mL})$ in the plasma at $2 \mathrm{~min}$, peaked at $5 \mathrm{~min}$, dropped again considerably at $10 \mathrm{~min}(63 \mathrm{ng} / \mathrm{mL})$, further to $27 \mathrm{ng} / \mathrm{mL}$ at $30 \mathrm{~min}$, and was undetectable at $1 \mathrm{~h}$ and beyond (Figure 2). Calculating with a $1 \mathrm{~mL}$ total peripheral blood volume (Joslin 2009) the $\mathrm{C}_{\max }$ of $8.9 \mu \mathrm{g} / \mathrm{mL}$ corresponds to approximately $22 \%$ injected peptide present in the circulation. The further reduced $t_{1 / 2}$ in live animals ( $4 \mathrm{~min}$, starting at the 2 min time point) compared to the stability in serum in vitro $(9 \mathrm{~min})$ is probably due to the very fast renal clearance of peptide drugs (Lister-James et al. 1996). Having said this, with a 1 min whole body blood circulation time in humans and less in mice, high concentrations of Allo-aca are able reach the cell surface ObR in most organs before it is eliminated in vivo. Indeed, near infrared fluorophorlabeled Allo-aca was found to be uniformly distributed in mice 15 min after intraperitoneal administration (Beccari et al. 2013). Nevertheless, the in vivo distribution data do not reveal total peptide concentration in the tissues, just the presence of the labeled peptide (or a shortened peptide carrying the Alexa-680 label) in any quantity that triggers fluorophor detector response.

Allo-aca binding to ObR. A biotin group was utilized to immobilize the Allo-aca peptide on NeutrAvidin SPR sensor surfaces. NeutrAvidin is a streptavidin derivative with reduced nonspecific binding properties, while retaining the extremely high affinity for biotin. Injection of ObR-LBD showed tight binding to the immobilized Allo-aca peptide (Figure 3). The obtained estimated dissociation rate constants $k_{\text {diss }}$ of $1.5 \pm 0.5 \times 10^{-4} \mathrm{~s}^{-1}$ and association rate constants $k_{\mathrm{a}}$ of $5.0 \pm 1.0 \times 10^{5} \mathrm{M}^{-1} \mathrm{~s}^{-1}$ were calculated from computational fitting of SPR traces using a simple biomolecular binding model. The calculated binding affinity $K_{\mathrm{d}}=k_{\mathrm{diss}} / k_{\mathrm{a}}$ is $0.3 \pm 0.15 \times 10^{-9} \mathrm{M}$ $(300 \mathrm{pM})$. Although the data could be fitted acceptably to a 1:1 binding model as suggested earlier to leptin protein and ObR (Mistrik et al. 2004), based on our SPR curves a two-step binding process in which the initial binding complex undergoes a slight rearrangement to form a final, more stable complex cannot be excluded either. Attempts to dissociate the ObR-LBD Allo-aca complex on the sensor chip by injection of an acidic regeneration buffer $(20 \mathrm{mM}$ glycine, $\mathrm{pH}$ 2.0) did not result in complete dissociation on the protein - peptide complex confirming the extremely tight Allo-aca - ObR binding.

\section{DISCUSSION}

In order to maximize the signal strength during SPR, we immobilized the Allo-aca peptide ligand to the chip surface. The SPR signal is proportional to the mass of the binding partner applied in the mobile phase, and when peptide-protein interactions are studied, usually the peptide component is immobilized (Kilko et al. 1993). In our case, the ObR LBD is about 25 times larger than Allo-aca. The biotin-labeled peptide analog was designed to maintain as much activity of the parent analog as possible and for optimal surface binding on the sensor chip. The first generation leptin receptor antagonist peptide Acal contains an N-terminal Thr instead of 
alloThr and displays a 20-fold reduction in cellular activities suggesting that the $\mathrm{N}$-terminal residue is involved in receptor binding (Otvos et al. 2011a). The N-terminal extension in peptide E1/Aca (Table 1) endows agonistic properties to the peptide further confirming the importance of the N-terminal region. Thus, we placed the biotin label to the C-terminus. The biotin moiety was attached to the side-chain of an extra lysine to provide a spacer between the NeutrAvidincoated chip and the peptide active site. Based on the cellular assay results of Table 2, biotin labeling still interfered with receptor binding, decreasing the activity figure by approximately 200 -fold. While the precise $\mathrm{IC}_{50}$ values rely of the cell line on leptin signaling for growth (although for us biotin labeling reduced the efficacy of Allo-aca against 2 completely different cell lines to identical degree), the number of receptors on the cell surface and other parameters, in ballpark, the $K_{\mathrm{d}}$ of the unlabeled peptide to ObR is estimated to be 200 -fold less than that we measured by SPR, i.e., at the single digit picomolar range. This value is exactly what was anticipated based on all cellular activity figures we collected so far.

To obtain accurate quantification of peptides in vitreous fluid and tear, we modified the protein precipitation step during the stability studies. Instead of 6-15\% TCA, proteins were precipitated with $89 \%$ acetonitrile and $1 \%$ formic acid. For antimicrobial peptides, this strategy improved the recovery yield from $1 \%$ to $100 \%$ (Knappe et al. 2010), and the protocol was also useful for pegylated peptides that are more hydrophobic than regular analogs, elute later on RP-HPLC and co-elute with serum components. In an earlier study using TCA as a protein precipitating agent, we could not recover any Allo-aca from mouse plasma when we tried to characterize the pharmacokinetic parameters (Otvos et al. 2011b). Then we hypothesized that the peptide binds to serum components in vivo (as opposed to the stability assay in pooled serum in vitro) and remains unseen later with the analytical protocol used. Applying the new protein precipitation technique to the PK assay as shown in the current report, we not only could recover high amounts of Allo-aca from mouse plasma and quantify the PK parameters, but taking into consideration the improvement of peptide yields in the above-listed examples, obtained further support for the Allo-aca serum binding process. In support, 8-20\% of exogenously added human leptin protein is found serum-bound in human blood ex vivo (Landt 2000).

During the calibration stage of the PK analysis, the limit of quantification (LOQ) was $0.5 \mathrm{ng}$ Allo-aca injected to the column ( $20 \mu \mathrm{L}$ injection volume) and the linear range extended until at least $200 \mathrm{ng}\left(\mathrm{R}^{2}=0.9949\right)$ analyte; that is the LOQ was around $25 \mathrm{ng} / \mathrm{mL}$ serum and the linear range extended to $10 \mu \mathrm{g} / \mathrm{mL}$. At the measurement stage signals from 2 to $30 \mathrm{~min}$ were within the linear range, whereas the quantities detected at time points 0, 60, 120 and 240 min were below the LOQ. With the used MS-HPLC pharmacokinetic measurement protocol, our $\mathrm{C}_{\max }$ was 5 min with approximately $10 \mu \mathrm{M}$ peptide after $2 \mathrm{mg} / \mathrm{kg}$ bolus peptide administration, and these figures compare very well to a $10-\mathrm{min} \mathrm{C}_{\max }$ of $37 \mu \mathrm{M}$ at a $6 \mathrm{mg} / \mathrm{kg}$ dose of a modified peptide prodrug determined by very similar analytical techniques (Janssen et al. 2006).

Our LOQ corresponds to approximately $25 \mathrm{nM}$ Allo-aca concentration in plasma. This sensitivity is approximately in the dynamic range of RP-HPLC-based peptide PK that has a lower limit of $10 \mathrm{ng} / \mathrm{mL}$ (in our case this is equivalent of $10 \mathrm{nM}$ Allo-aca) in validated pharmaceutical protocols (Zannikos et al. 2000). However, receptor agonist and antagonist peptide drugs act in the pM range, and expectedly Allo-aca was present in the blood at a concentration higher than the $100-500 \mathrm{pM} \mathrm{IC}_{50}$ value well beyond the 30 min mark that roughly 
corresponded to our LOQ. The situation is less problematic in humans where higher blood volumes are available than in rodents, although the required drug doses in humans are about 12fold lower than in mice due to differences in the body surface area/weight ratio (Reagan-Shaw et al. 2008). Human serum concentrations of triptorelin, a 10-residue agonist of the gonadotropinreleasing hormone receptor, of $8 \mathrm{ng} / \mathrm{mL}$ are already associated with activation of $90 \%$ of the receptor population, and higher peptide concentrations are not expected to induce any stronger biological responses (Romero et al. 2012). In turn, even if we can push the sensitivity of the murine PK quantification protocol down by a magnitude, we will still miss later time points when Allo-aca, or similar highly active peptide drugs, are present in the circulation above their $\mathrm{IC}_{50} / \mathrm{EC}_{50}$ figures. Taken together, current RP-HPLC peptide PK protocols, where the analytes are not radioactively labeled, cannot accurately predict the real time while peptide drugs are active in rodent models.

While various peptides exhibit up to 3-fold species-dependent stability half-life differences in mammalian sera in vitro (McDermott et al. 1981), in our hands and protocols used by us, these are not significant between pooled commercial human and mouse serum preparations (Hoffmann et al. 1999). Allo-aca degraded in diluted human serum in less than $1 \mathrm{~h}$ with improved stability in bovine vitreous fluid. The highest stability of Allo-aca ( $>10 \mathrm{~h}$ half-life) was observed in human tears. Understanding that the tear turnover in vivo is $11 \% / \mathrm{min}$ in healthy people (Sorbara et al. 2004) and less than 5\% of topically applied protein-based drug penetrates the cornea and reaches intraocular compartments (Ottinger et al. 2009) Allo-aca stability in ophthalmic fluids is not the bottleneck in potential therapeutic applications. Although the drugs instilled into the eye as eye drops are available for activity only for a limited time period, intravitreal injection of bevacizumab, an angiogenesis inhibitor monoclonal antibody drug allows systemic distribution as much as higher plasma than eye content is observed between 4 and 8 weeks after administration (Miyake et al. 2010), indicating activity longer than any ocular turnover would warrant it.

Most leptin receptor antagonist peptides and some mutant proteins exhibit partial agonist properties depending upon their test concentrations and other receptor ligands available in the assay milieu (Otvos et al. 2008). In all earlier cell systems, Allo-aca distinguished itself from other ObR antagonists with its large concentration window (>1000-fold) from going from antagonist to agonist. Against the K-562 CML cell line as presented here, the peptide either retained anti-proliferative activity without exogenous leptin added, or exhibited a narrower concentration window ( $\square$ 100-fold) before it stimulated rather than inhibited cell growth. The low concentration agonistic contribution has to be taken into account when designing Allo-aca doses in hematological animal models. In different breast cancer and arthritis systems Allo-aca shows ObR antagonist properties at $0.1 \mathrm{mg} / \mathrm{kg}$ and $1 \mathrm{mg} / \mathrm{kg}$ daily doses with little dosedependence (Otvos et al. 2011a; Otvos et al. 2011b; Otvos et al. 2011c). In vivo, the Allo-aca antagonist $\rightarrow$ agonist switch takes place above $10 \mathrm{mg} / \mathrm{kg}$ in the orexigenic test (Otvos et al. $2011 \mathrm{~b}$ ) and is more observable (at $1 \mathrm{mg} / \mathrm{kg}$ ) in close analog peptides containing D-amino acid replacements that exhibit low pM cellular activity and are shown to bind ObR in 3-dimensional cultures (Beccari et al. 2013). When calculating from the approximately $9 \mu \mathrm{g} / \mathrm{mL}$, i.e., $9 \mu \mathrm{M}$ peak plasma concentration of the PK assay ran at a $2 \mathrm{mg} / \mathrm{kg}$ dose, even at $0.1 \mathrm{mg} / \mathrm{kg}$ the peak Allo-aca plasma concentration should be around $500 \mathrm{nM}$, which falls into the antagonist range against MCF-7 breast cancer cells, but is in the agonist range for K-562 leukemia cells. 
Accordingly, the planned antagonist doses in hematological cancers (and likely other cardiovascular applications) have to be lowered compared to those against solid tumors.

The most significant finding of the current report is the extreme stability of the complex between the leptin antagonist peptide and the ligand binding domain of the receptor. The half-life of the Allo-aca - ObR LBD complex was almost $2 \mathrm{~h}$, indicating that Allo-aca keeps ObR deactivated for about 4 hours, and due to the high homology between Allo-aca our ObR antagonist peptide and E1/Aca the ObR agonist analog (Kovalszky et al. 2010), we expect similar values for the agonist as well. As compared with earlier SPR studies between different ObR forms and the full leptin protein ligand, Allo-aca dissociates from the complex slower than leptin itself, in spite of utilizing only 1 of the 3 ObR-binding sites (Table 3). Moreover, the C-terminal biotin label on the peptide is expected to decrease the binding efficiency more than derivatization through some of amino groups on the ligand (Sandowski et al. 2002) or incorporation an IgG Fc-fragment to the receptor (Mistrik et al. 2004). Apparently the non-natural amino acid replacements in Alloaca (Thr $\rightarrow$ alloThr, Val $\rightarrow$ Nva and Leu $\rightarrow$ Aca) (Otvos et al. 2011a) endow the peptide with increased ability to bind the receptor compared the natural counterpart (Table 1). The pharmaceutical relevance for this very strong binding for example is underlined by the observation that Allo-aca remains bound to ObR for a significantly longer period of time measured by SPR than a longer endostatin peptide, considered for further drug development, to its target vascular endothelial growth factor receptor type 3 (Han et al. 2010).

The very strong binding between Allo-aca and ObR explains all the remarkable in vivo efficacy data (Otvos et al. 2011a; Otvos et al. 2011b; Otvos et al. 2011c) in spite of the relatively fast degradation in human serum in vitro and in mouse plasma in vivo. In general, for Allo-aca and probably for many other peptide drug leads, stability data (as we measure them today) in various biological fluids has less predictive value for in vivo efficacy than previously thought. Peptides excel in terms of high activity and selectivity to their targets (Albericio and Kruger 2012) and thus, may activate or inactivate receptor functions considerably longer than molecular and cellular turnovers (including their own degradation and elimination) take place in experimental animals or human and veterinary patients.

\section{ACKNOWLEDGEMENTS}

This work was partially supported by the Novo Nordisk Diabetes Innovation Award to E.S. Another part of this work was supported by Australian Research Council Discovery grant DP120101963 to J.D.W. who is also an NHMRC (Australia) Principal Research Fellow.

\section{CONFLICT OF INTEREST}

The authors declare no competing financial interests.

\section{REFERENCES}


Albericio F, Kruger HG, (2012) Therapeutic peptides. Future Med Chem 4:1527-1531.

Beccari S, Kovalszky I, Wade JD, Otvos L Jr, Surmacz E (2013) Designer peptide antagonist of the leptin receptor with peripheral antineoplastic activity. Peptides 44:127-134.

Carpenter B, Hemsworth GR, Wu Z, Maamra M, Strasburger CJ, Ross RJ, Artymiuk PJ (2012) Structure of the human obesity receptor leptin-binding domain reveals the mechanism of leptin antagonism by a monoclonal antibody. Structure 20:487-497.

Fields GB, Noble RL (1990) Solid-phase peptide synthesis using 9-fluorenylmethoxycarbonyl amino acids. Int J Pept Protein Res 35:161-214.

Frey WH $2^{\text {nd }}$, DeSota Johnson D, Hoffmann C, McCall JT (1981) Effect of stimulus on the chemical composition of human tears. Am J Ophthalmol 92:559-567.

Gonzalez RR, Cherfils S, Escobar M, Yoo JH, Carino C, Styer AK, Sullivan BT, Sakamoto H, Olawaiye A, Serikawa T, Lynch MP, Rueda RR (2006) Leptin signaling promotes the growth of mammary tumors and increases the expression of vascular endothelial growth factor (VEGF) and its receptor type two (VEGF-R2). J Biol Chem 281:26320-26328.

Gonzalez RR, Watters A, Xu Y, Singh UP, Mann DR, Rueda BR, Penichet ML (2009) Leptinsignaling inhibition results in efficient anti-tumor activity in estrogen receptor positive or negative breast cancer. Breast Cancer Res 11:R36.

Han KY, Azar DT, Sabri A, Lee H, Jain J, Lee BS, Chang JH (2010) Characterization of the interaction between endostatin short peptide and VEGF receptor 3. Protein Pept Lett 19:969-974.

Hoffman R, Bulet, P, Urge L, Otvos L., Jr. (1999) Range of activity and metabolic stability of synthetic antibacterial glycopeptides from insects. Biochim Biophys Acta 1426:459-467.

Inui A, Meguid MM (2003) Cachexia and obesity: two sides of one coin? Curr Opin Clin Nutr Metab Care 6:395-399.

Joslin JO (2009) Blood collection techniques in exotic small mammals. J Exotic Pet Med 18:117-139.

Janssen S, Rosen DM, Ricklis RM, Dionne CA, Lilja H, Christensen SB, Isaacs JT, Denmeade SR (2006) Pharmacokinetics, biodistribution, and antitumor efficacy of a human glandural kallikrenin 2 (hK2)-activated thapsigargin prodrug. The Prostate 66:358-368.

Kalra SP (2008) Central leptin insufficiency syndrome: an interactive etiology for obesity, metabolic and neural diseases and for designing new therapeutic interventions. Peptides 29:127138. 
Kilko SN, Corr M, Boyd LF, Lees A, Inman JK, Margulies DH (1993) Direct detection of major histocompatibility complex class I binding to antigenic peptides using surface plasmon resonance. Peptide immobilization and characterization of binding specificity. J Biol Chem 268:15425-15434.

Knappe D, Henklein P, Hoffmann R, Hilpert K (2010) Easy strategy to protect antimicrobial peptides from fast degradation in serum. Antimicrob Agents Chemother 54:4003-4005.

Kovalszky I, Surmacz E, Scolaro L, Cassone M, Sztodola A, Olah J, Hatfield MP, Lovas S, Otvos L Jr (2010) Leptin-based glycopeptide induces weight loss and simultaneously restores fertility in animal models. Diabetes Obes Metab 12:393-402.

Landt M (2000) Leptin binding and binding capacity in serum. Clin Chem 46:379-384.

Liao S, Qie JK, Xue M, Zhang ZQ, Liu KL, Ruan JX (2010) Metabolic stability of human parathyroid hormone peptide hPTH (1-34) in rat tissue homogenates: kinetics and products of proteolyitic degradation. Amino Acids 38:1595-1605.

Lister-James J, Moyer BR, Dean T (1996) Small peptides radiolabeled with 99mTc. Q J Nucl Med 40:221-233.

Martins I, Gomez S, Costa RO, Otvos L, Oliveira CR, Resende R, Pereira CMF (2013) Leptin and ghrelin prevent hippocampal dysfunction induced by A $\beta$ oligomers. Neurosci 241:41-51.

McDermott JR, Smith AI, Biggins JA, Hardy JA, Dodd PR, Edwardson JA (1981) Degradation of luteinizing hormone-rleasing hormone by serum and plasma in vitro. Regul Pept 2:69-79.

Mistrik P, Moreau F, Allen JM (2004) BiaCore analysis of leptin-leptin receptor interaction: evidence for 1:1 stoichiometry. Anal Biochem 327:271-277.

Miyake T, Sawada O, Kakinoki M, Sawada T, Kawamura H, Ogasawara K, Ohji M (2010) Pharmacokinetics of bevacizumab and its effect on vascular endothelial growth factor after intravitreal injection ofbevacizumab in macaque eyes. Invest Ophthalmol Vis Sci 51:1606-1608.

Moulin A, Brunel L, Boeglin D, Demange L, Ryan J, M'Kadmi C, Denoyelle S, Martinez J, Fehrentz JA (2013) The 1,2,4-triazole as a scaffold for the design of ghrelin receptor ligands: development of JMV 2959, a potent antagonist. Amino Acids 44:301-314.

Ottiger M, Thiel MA, Feige U, Lichtlen P, Urech DM (2009) Efficient intraocular penetration of topical anti-TNF-alpha single-chain antibody (ESBA105) to anterior and posterior segment without penetration enhancer. Invest Ophthalmol Vis Sci 50:779-586.

Otvos L Jr, Terrasi M, Cascio S, Cassone M, Abbadessa G, di Pascali F, Scolaro L, Knappe D, Stawikowski M, Cudic P, Wade JD, Hoffmann R, Surmacz E. (2008) Development of a pharmacologically improved peptide agonist of the leptin receptor. Biochim. Biophys. Acta 1783:1745-1754. 
Otvos L Jr, Kovalszky I, Scolaro L, Sztodola A, Olah J, Cassone M, Knappe D, Hoffmann R, Lovas S, Hatfield MP, Beko G, Zhang S, Wade JD, Surmacz E (2011a) Peptide-based receptor antagonists for cancer treatment and appetite regulation. Biopolymers 96:117-125.

Otvos L Jr, Kovalszky I, Riolfi M, Ferla R, Olah J, Sztodola A, Nama K, Molino A, Piubello Q, Wade JD, Surmacz E (2011b) Efficacy of a leptin receptor antagonist peptide in a mouse model of triple-negative breast cancer. Eur J Cancer 47:1578-1584.

Otvos L Jr, Shao W-H, Vanniasinghe A, Amon MA, Holub MC, Kovalszky I, Wade JD, Doll M, Cohen PL, Manolios N, Surmacz E (2011c) Toward understanding the role of leptin and leptin receptor antagonism in preclinical models of rheumatoid arthritis. Peptides 32:1567-1567.

Otvos Jr L, Surmacz E (2011) Targeting the leptin receptor: a potential new mode of treatment for breast cancer. Expert Rev Anticancer Ther 11:1147-1150.

Ozturk K, Avcu F, Ural AU (2012) Aberrant expressions of leptin and adiponectin receptor isoforms in chronic myeloid leukemia patients. Cytokine 57:61-67.

Peelman F, Van Beneden L, Zabeau H, Iserentant H, Ulrichts P, Defeau D, Verhee A, Catteeuw D, Elewaut D, Tavernier JF (2004) Mapping of the leptin binding sites and design of a leptin antagonist. J Biol Chem 279:41038-41046.

Powell MF, Grey H, Gaeta F, Sette A, Colon SM (1992) Peptide stability in drug development: a comparison of peptide reactivity in different biological media. J Pharm Sci 81:731-735.

Powell MF, Stewart T, Otvos L Jr, Urge L, Gaeta F, Sette A, Arrhenius T, Thomson D, Soda K, Colon SM (1993) Peptide stability in drug development. II. Effect of single amino acid substitution and glycosylation peptide reactivity in human serum. Pharmacol Res 10:1268-1273.

Reagan-Shaw S, Nihal M, Ahmad N (2008) Dose translation from animal to human studies revisited. FASEB J 22:569-661.

Romero E, Velez de Mendizabal N, Cendros JM, Peraire C, Bascompta E, Obach R, Troconiz IF (2012) Pharmacokinetic/pharmacodynamic model of the testosterone effects of triptorelin administered in sustained release formulations in patients with prostate cancer. $\mathrm{J}$ Pharmacol Exp Ther 342:788-798.

Sandowski Y, Raver N, Gussakovski, E.E, Shochat S, Dym O, Livnah O, Rubinstein M, Krishna R, Gertler A (2002) Subcloning, expression, purification, and characterization of recombinant human leptin-binding domain. J Biol Chem 277:46304-46309.

Scolaro L, Parrino C, Coroniti R, Otvos L Jr, Surmacz E (2013) Exproling leptin antagonism in ophthalmic cell models. PLoS One 8:e76437. 
Shpilman M, Niv-Spector L, Katz M, Varol C, Solomon G, Ayalon-Soffer M, Boder E, Halpern Z, Elinav E, Gertler AM (2011) Development and characterization of high affinity leptins and leptin antagonists. J Biol Chem 286:4429-4442.

Sorbara L, Simpson T, Vaccari S, Jones L, Fonn D (2004) Tear turnover rate is reduced in patients with symptomatic dry eye. Cont Lens Anterior Eye 27:15-20.

Wauters M, Considine RV, Van Gaal LF (2000) Human leptin: from an adipocyte hormone to an endocrine mediator. Eur J Endocrinol 143:293-311.

Werle M, Bernkop-Schnurch A (2006) Strategies to improve plasma half life time of peptide and protein drugs. Amino Acids 30:351-367.

Zannikos PN, Rohatagi S, Jensen BK, DePhillips SL, Rhodes GR, Pharmacokinetics and concentration-effect analysis of intravenous RGD891, a platelet GPIIb/IIIa antagonist, using mixed-effects modeling (NONMEM). J Clin Pharmacol 40:1129-1140.

Table 1. Peptides used in this study and their relationship to the native leptin site III sequence and other ObR-binding site III leptin receptor response modifier peptides. $\operatorname{Tyr}\left(\mathrm{I}_{2}\right)$ : 3,5-diiodotyrosine; Thr $\alpha(\mathrm{GalNAc})$ : O- $\alpha$-N-acetyl galactosamine-linked to threonine; the abbreviations for other non-natural amino acids are detailed in the text.

\begin{tabular}{|l|c|}
\hline Peptide & Sequence \\
\hline Human leptin 121-129 & Thr-Glu-Val-Val-Ala-Leu-Ser-Arg-Leu \\
\hline E1/Aca pM agonist & H-Tyr(I $\mathrm{I}_{2}$-Ser-Thra(GalNAc)-Glu-Val-Val-Ala-Leu-Ser-Arg-Aca-NH \\
\hline Aca1 nM antagonist & H-Thr-Glu-Nva-Val-Ala-Leu-Ser-Arg-Aca-NH \\
\hline Allo-aca pM antagonist & H-alloThr-Glu-Nva-Val-Ala-Leu-Ser-Arg-Aca-NH \\
\hline Allo-aca(biotin) & H-alloThr-Glu-Nva-Val-Ala-Leu-Ser-Arg-Aca-Lys(biotin)-NH \\
\hline
\end{tabular}

${ }^{\mathrm{a}}$ Numbering is from Peelman et al. 2004. 
Table 2. Stability of leptin receptor antagonist in various biological media and in vitro activity of analogs in cellular tumor models.

\begin{tabular}{|l|c|c|c|c|c|}
\hline Peptide & $\begin{array}{c}\text { Half-life } \\
\text { in mouse } \\
\text { serum }\end{array}$ & $\begin{array}{c}I C_{50} / E C_{50} \text { in } \\
\text { KL562 model }\end{array}$ & $\begin{array}{c}\text { Control IC } C_{50} / E C_{50} \\
\text { in MCF-7 model }\end{array}$ & $\begin{array}{c}\text { Half-life in } \\
\text { bovine vitreous } \\
\text { fluid }\end{array}$ & $\begin{array}{c}\text { Half-life in } \\
\text { human tear }\end{array}$ \\
\hline Allo-aca & $9 \mathrm{~min}^{\mathrm{b}}$ & $0.1 / 10 \mathrm{nM}$ & $0.5 />100 \mathrm{nM}$ & $2.2-2.8 \mathrm{~h}$ & $10.2 \mathrm{~h}$ \\
\hline Allo-aca(biotin) & & $20 />100 \mathrm{nM}$ & $100 />1000 \mathrm{nM}$ & n.d. ${ }^{\mathrm{c}}$ & n.d. \\
\hline
\end{tabular}

${ }^{\mathrm{b}}$ Calculated from 36 min $\mathrm{t}_{1 / 2}$ measured in $25 \%$ aqueous mouse serum based on Powell et al. 1992. ${ }^{c}$ not determined.

Table 3. A comparison of surface plasmon resonance-based binding data of leptin receptor ligand complexes.

\begin{tabular}{|l|l|l|c|c|c|c|}
\hline Ligand & Receptor form & $\begin{array}{l}\text { Immobilized/ } \\
\text { Derivatization }\end{array}$ & $\begin{array}{c}k_{a} \\
\left(M^{-1} s^{-1}\right)\end{array}$ & $\begin{array}{c}k_{d} \\
\left(s^{-1}\right)\end{array}$ & $\begin{array}{c}K_{d} \\
(p M)\end{array}$ & Reference \\
\hline Allo-aca peptide & ObR LBD & Ligand/biotin & $5 \times 10^{5}$ & $1.5 \times 10^{-4}$ & 300 & Herein \\
\hline Leptin protein & ObR extracellular & Receptor/Fc & $1.9 \times 10^{6}$ & $4.4 \times 10^{-4}$ & 230 & ${ }^{\mathrm{a}}$ \\
\hline Leptin protein & ObR LBD & Ligand/amino groups & $1.2 \times 10^{5}$ & $1.9 \times 10^{-3}$ & 15000 & ${ }^{\mathrm{b}}$ \\
\hline
\end{tabular}

${ }^{\mathrm{a}}$ Mistrik et al. 2004

${ }^{\mathrm{b}}$ Sandowski et al. 2002 
Figure Legend:

Figure 1: Stability of peptide Allo-aca in bovine vitreous fluid extracted from fresh bovine eyes. The figure shows the degradation kinetics of the peptide from the vitreous fluid from one eye, taken from triplicate samples. Identical assays from the second eye showed very similar kinetics albeit with somewhat faster degradation times. The error bars indicate the standard deviation of triplicate parallels.

Figure 2: Pharmacokinetics of peptide Allo-aca injected into CD-1 mice at $2 \mathrm{mg} / \mathrm{kg}$ subcutaneously. The peptide concentrations from samples taken from the tail vein were quantified by a combination of nano-high performance liquid chromatography and mass spectrometry. The peptide amount peaked at $5 \mathrm{~min}$ with very small quantities detectable at 2 min and 10-30 min. Peptide amounts at $0 \mathrm{~min}$ and beyond $1 \mathrm{~h}$ were below the detection limit of $25 \mathrm{ng} / \mathrm{mL}$. Each time point represents the peptide amounts detected in a mixture of blood taken from 3 animals. The plasma peptide concentration determination was repeated from frozen samples with very similar kinetic results.

Figure 3: Representative surface plasmon resonance (SPR) blank corrected difference trace (left channel - right channel) showing the association and dissociation phase of the interaction between the leptin binding domain of the human leptin receptor and the Allo-aca peptide immobilized via a C-terminal biotin-lysine modification onto a NeutrAvidin coated SPR sensor chip. The estimated binding affinity $K_{\mathrm{d}}$ for the protein - peptide complex is $0.3 \mathrm{nM}$ and the dissociation rate constant $\left(k_{\text {diss }}\right)$ of $1.5 \times 10^{-4} \mathrm{~s}^{-1}$ corresponds to a half-life of the complex of close to 2 hours (111 min). 
Figure 1:

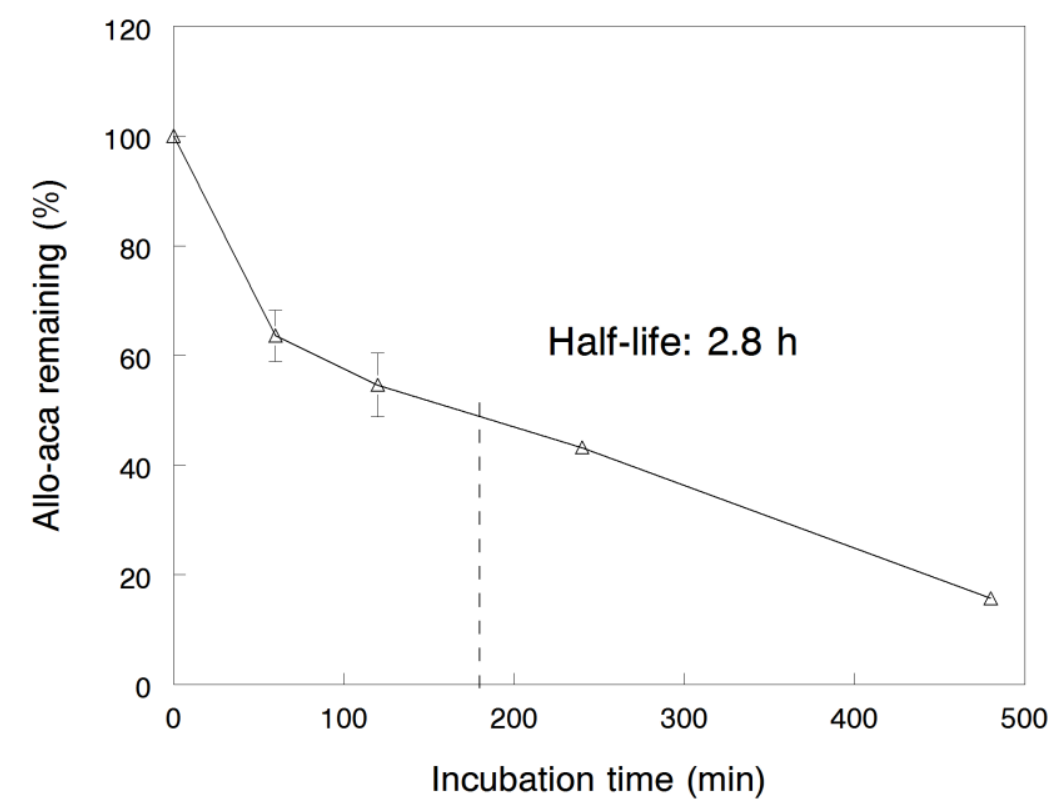

Figure 2:

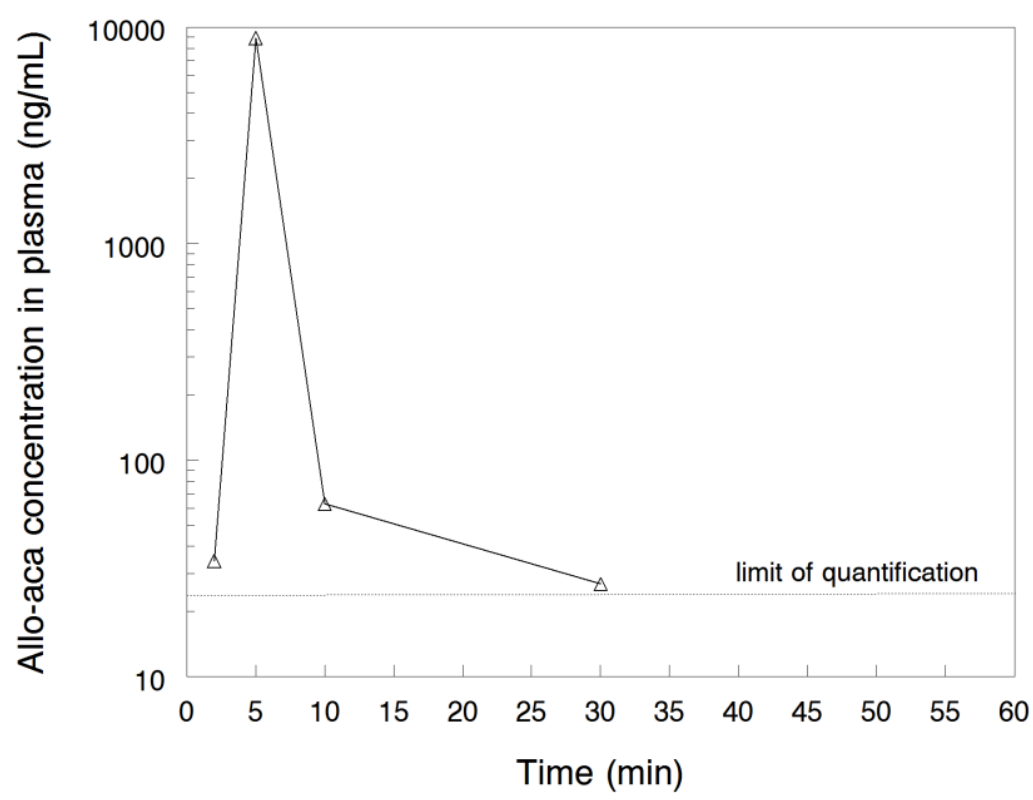


Figure 3:

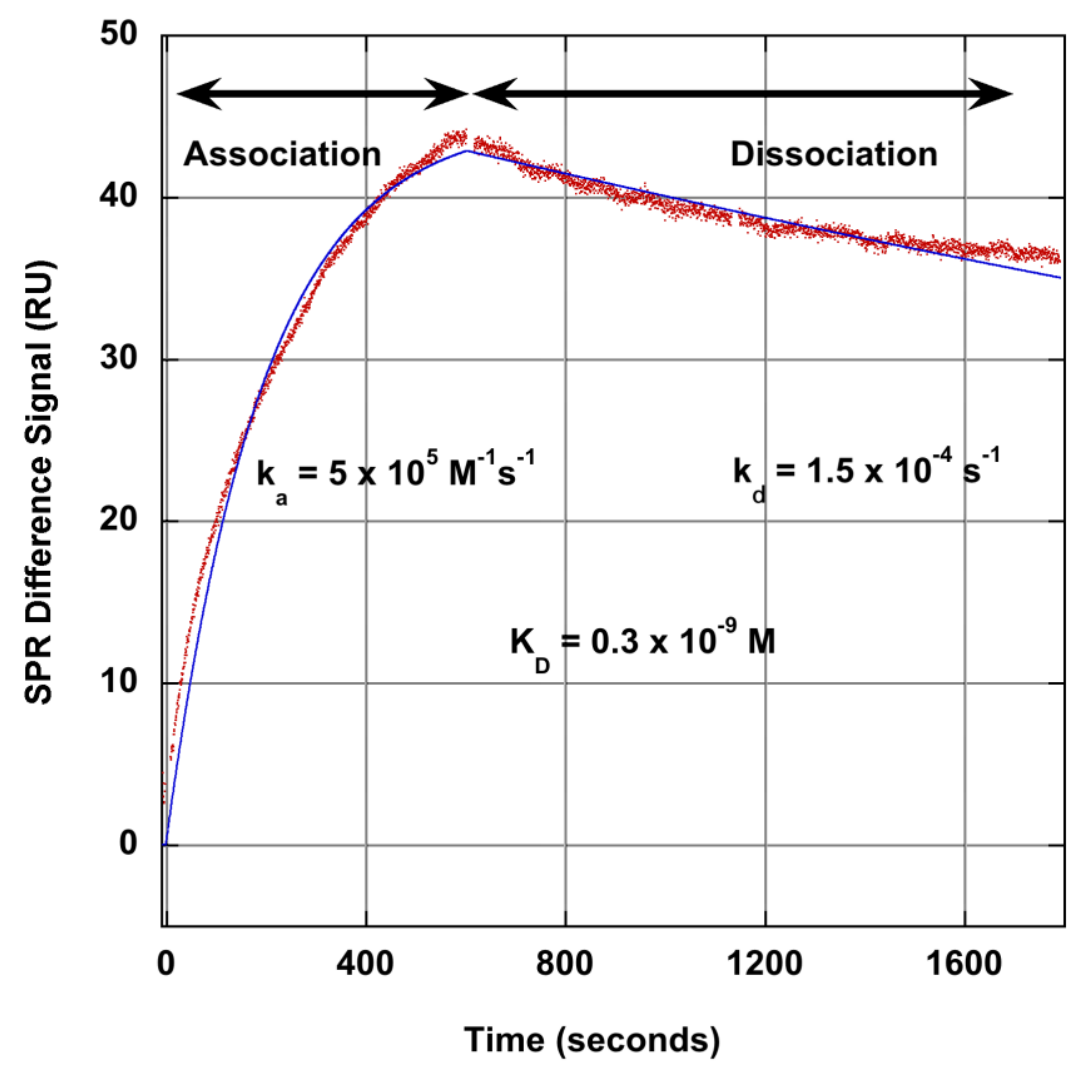




\section{University Library}

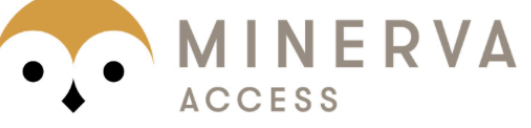

A gateway to Melbourne's research publications

Minerva Access is the Institutional Repository of The University of Melbourne

\section{Author/s:}

Otvos, L;Vetter, SW;Koladia, M;Knappe, D;Schmidt, R;Ostorhazi, E;Kovalszky, I;Bionda, N;Cudic, P;Surmacz, E;Wade, JD;Hoffmann, R

Title:

The designer leptin antagonist peptide Allo-aca compensates for short serum half-life with very tight binding to the receptor

\section{Date:}

2014-04-01

\section{Citation:}

Otvos, L., Vetter, S. W., Koladia, M., Knappe, D., Schmidt, R., Ostorhazi, E., Kovalszky, I., Bionda, N., Cudic, P., Surmacz, E., Wade, J. D. \& Hoffmann, R. (2014). The designer leptin antagonist peptide Allo-aca compensates for short serum half-life with very tight binding to the receptor. AMINO ACIDS, 46 (4), pp.873-882. https://doi.org/10.1007/ s00726-013-1650-6.

Persistent Link:

http://hdl.handle.net/11343/282646 